\title{
Comparison between catalytic and catalytic photo-assisted propene hydration by using supported heteropolyacid
}

\author{
Giuseppe Marcìa,b,* Elisa Isabel García-López $^{\mathrm{a}, \mathrm{b}}$, Leonardo Palmisano ${ }^{\mathrm{a}, \mathrm{b}}$ \\ a "Schiavello-Grillone” Photocatalysis Group, Dipartimento di Ingegneria Elettrica, Elettronica e delle Telecomunicazioni, di tecnologie Chimiche, \\ Automatica e modelli Matematici (DIEETCAM), Università di Palermo, Viale delle Scienze, 90128 Palermo, Italy \\ ${ }^{\mathrm{b}}$ Consorzio Interuniversitario Nazionale “La Chimica per l'Ambiente" (INCA), Via delle Industrie 21/8, 30175 Marghera (VE), Italy
}

\section{A R T I C L E I N F O}

\section{Article history:}

Received 7 November 2011

Received in revised form 26 January 2012

Accepted 30 January 2012

Available online 7 February 2012

\section{Keywords:}

Heteropolyacid

Propene

Hydration

2-propanol

Photo-assisted reaction

$\mathrm{TiO}_{2}$

\begin{abstract}
A B S T R A C T
Hybrid materials have been prepared by impregnation of the heteropolyacid $\mathrm{H}_{3} \mathrm{PW}_{12} \mathrm{O}_{40}$ on commercial $\mathrm{TiO}_{2}$. The polyoxometalates (POM) amount deposited was $15,30,50$ and $70 \%$ with respect to the weight of the $\mathrm{TiO}_{2}$ support. Moreover two samples containing a POM amount of 15 , and $50 \%$ with respect to the weight of $\mathrm{SiO}_{2}$ were also prepared for the sake of comparison. All prepared samples were efficient catalysts for the hydration of propene to 2-propanol in gas-solid regime at atmospheric pressure and at temperatures ranging between 50 and $85^{\circ} \mathrm{C}$. The study carried out on the hybrid $\mathrm{TiO}_{2}$ based materials evidenced that, as far as the catalytic activity is concerned, exists an optimum in the amount of POM. Notably the contemporary presence of heat and UV light improved the activity of the $\mathrm{POM} / \mathrm{TiO}_{2}$ and $\mathrm{POM} / \mathrm{SiO}_{2}$ materials, although $\mathrm{POM} / \mathrm{TiO}_{2}$ showed better catalytic and catalytic photo-assisted activity than $\mathrm{POM} / \mathrm{SiO}_{2}$. POM species played a key role in both the catalytic and photo-assisted catalytic reactions, due to its surface acidity and ability to form strong oxidant species under UV irradiation. The presence of $\mathrm{TiO}_{2}$ under UV irradiation improved the heteropolyacid performance supplying conduction band electrons to the POM.
\end{abstract}

(C) 2012 Elsevier B.V. All rights reserved.

\section{Introduction}

The hydration of propene at ambient conditions is a reaction of great interest. The industrial propene catalytic hydration to 2propanol is carried out at moderate temperatures (ca. $150-200^{\circ} \mathrm{C}$ ) and pressure ( $2 \mathrm{MPa}$ ) in the presence of an acid catalyst as phosphoric acid supported on silica, strong acidic resins [1], beta zeolite [2] and other acidic zeolites [3], whereas the reverse reaction, i.e. the dehydration of 2-propanol is a reaction frequently used for the characterization of the acidic character of catalysts, as for instance supported heteropolyacids. The last reaction gives rise to formation of propene at atmospheric pressure and temperatures ranging between 140 and $325^{\circ} \mathrm{C}$ [4]. The propene hydration is not an easy reaction to be carried out, because thermodynamically limited by the mentioned reverse reaction at high temperature. Heteropolyacids, also called polyoxometalates (POMs), are catalysts industrially used for the hydration of propene to 2-propanol. POMs

\footnotetext{
* Corresponding author at: "Schiavello-Grillone" Photocatalysis Group, Dipartimento di Ingegneria Elettrica, Elettronica e delle Telecomunicazioni, di tecnologie Chimiche, Automatica e modelli Matematici (DIEETCAM), Università di Palermo, Viale delle Scienze, 90128 Palermo, Italy. Tel.: +39 091 23863737; fax: +3909123860841.

E-mail address: giuseppe.marci@unipa.it (G. Marcì).
}

are generally used in solution as acid and oxidation catalysts. They are very strong Brönsted acids and efficient oxidants that perform fast and reversible redox multielectronic transformations under mild conditions; consequently they can act as bifunctional catalysts [5]. The industrial hydration of propene to obtain 2-propanol has been carried out by using aqueous solutions of $\mathrm{H}_{3} \mathrm{PW}_{12} \mathrm{O}_{40}$. The catalytic reaction performed in gas-solid regime has been the object of several patents [6,7], but only very few papers have been published. Ivanov et al. compared the catalytic activity of acidic zeolite HZSM5 with non-supported and supported $\mathrm{H}_{3} \mathrm{PW}_{12} \mathrm{O}_{40}$ (10\% and 70\% weight of $\mathrm{POM}$ on $\mathrm{SiO}_{2}$ ) for propene hydration reaction to obtain 2-propanol [8]. Supported POM resulted much more active than the bare corresponding sample and the HZSM-5, substantially due to their stronger acidity. The POM based materials showed a significant activity only from $100^{\circ} \mathrm{C}$. The maximum activity in hydration was measured at $130^{\circ} \mathrm{C}$, further increase of the temperature led to a decrease in the rate of 2-propanol formation due to the significant occurrence of the reverse dehydration reaction. The 70\% $\mathrm{POM} / \mathrm{SiO}_{2}$ material showed a significant higher activity than the $10 \% \mathrm{POM} / \mathrm{SiO}_{2}$ or the bulk POM.

Dispersing POMs onto solid supports with high surface area is generally useful to increase their specific surface area and hence catalytic activity. Acidic or neutral substances as $\mathrm{SiO}_{2}$, active carbon, acidic ion-exchange resin have been used as supports, whereas basic solids as $\mathrm{Al}_{2} \mathrm{O}_{3}$ or $\mathrm{MgO}$ have been reported to induce POM 
decomposition [5]. Pizzio et al. [9] studied $\mathrm{H}_{3} \mathrm{PW}_{12} \mathrm{O}_{40}$ impregnated on carbon, $\mathrm{TiO}_{2}$ and $\mathrm{SiO}_{2}$ for 2-propanol dehydration. They observed that the main species present on the composite was the anion of the acid that was thermally stable up to $425^{\circ} \mathrm{C}$ when supported on carbon and $\mathrm{TiO}_{2}$, while on $\mathrm{SiO}_{2}$ it underwent partial degradation starting from $365^{\circ} \mathrm{C}$.

Considering the effect of irradiation on the catalytic system, a high amount of studies have investigated the heterogeneous photocatalytic process by semiconductor oxides applied to degrade organic and inorganic pollutants both in vapour and in liquid phases [10]. The main advantages of photocatalysis consist not only in the mild conditions under which the process can be carried out, but also in the possibility to abate refractory, very toxic and not biodegradable molecules. Many semiconductor materials have been tested as photocatalysts but it is generally accepted that $\mathrm{TiO}_{2}$ is the most reliable material and it can be used under UV irradiation at wavelengths shorter than $385 \mathrm{~nm}$, corresponding to its band-gap. The catalytic photo-assisted reaction occurs on semiconductor irradiated with energy higher or equal to the band gap $\left(E_{\mathrm{g}}\right)$, causing the formation of holes $\left(\mathrm{h}^{+}\right)$in he valence band and electrons $\left(\mathrm{e}^{-}\right)$in the conduction band, where both positive holes and hydroxyl radicals have been proposed as the oxidizing species responsible for initiating the degradation of the organic substrates. In the presence of water, the holes can be efficiently scavenged and strong and unselective oxidant $\mathrm{OH}$ radicals, able to attack the organic substrates to be degraded are produced [10]. Notably catalytic photo-assisted reactions are carried out at atmospheric pressure and room temperature because the photonic activation of the photocatalyst does not require heating. The true activation energy of the process is nil whereas the apparent activation energy is small (few $\mathrm{kJ} / \mathrm{mol}$ ) in the temperature range $20-80^{\circ} \mathrm{C}$ [11]. The whole process can be divided in four steps: absorption of light followed by separation of electron-hole pairs, adsorption of the reagents, redox reaction, desorption of the products. By heating the system the adsorption process becomes the rate limiting step and consequently the activity of the system decreases; however, by using POM containing solids, due to the well know ability of POM to absorb polar molecules forming the so-called "pseudo-liquid" [5] phase, a particular view of the adsorption interaction sorbent-surface could be considered because toward polar substances, solid heteropolyacids behave like highly concentrated solutions.

Anatase $\mathrm{TiO}_{2}$ is the most widely investigated heterogeneous semiconductor photocatalyst while POMs have been studied as a homogeneous photocatalyst as well. In fact, POM systems share electronic features and hence photochemical characteristics with the semiconductor photocatalysts. The band gap energy and the band edge positions of homogeneous POM photocatalyst, $\mathrm{PW}_{12} \mathrm{O}_{40}{ }^{3-}$, are not much different from those of $\mathrm{TiO}_{2}$ anatase and rutile (3.2 and $3.0 \mathrm{eV}$, respectively) [12,13]. The absorption of light by the ground electronic state of the solubilized POM producing the charge transfer-excited state $\mathrm{POM}^{*}$ (this ligand to charge transfer band can be observed at $260 \mathrm{~nm}$ corresponding to $4.8 \mathrm{eV}$ ) is qualitatively analogous to the absorption of band gap radiation by a solid semiconductor metal oxide producing a transient electron-hole pair. Likewise substrate oxidation by the excited state of the polyoxometalate is analogous to the corresponding process in semiconductors [14]. The metal ions in the POM have $\mathrm{d}^{0}$ electronic configurations and the energy absorption occurs when electrons are promoted from the low energy electronic states (oxygen $2 p$ orbitals, i.e. the valence band in the band model) to the high-energy electronic states (metal d orbitals, i.e. the conduction band in the band model). The POM* excited state is a better oxidant and reductant species with respect to the corresponding ground states [15]; hence under near-UV irradiation a generic POM becomes $\mathrm{POM}^{-}$a "heteropoly blue" species by means of one (or more) electron transfer from another species [16]. Heteropoly blue species are relatively stable, absorb visible light $\left(\mathrm{PW}_{12} \mathrm{O}_{40}{ }^{4-}\right.$ at $650 \mathrm{~nm}$ ) and are readily reoxidized to $\mathrm{PW}_{12} \mathrm{O}_{40}{ }^{3-}$ by transferring electrons to electron acceptors. This photo-reduction of POM is synergistically enhanced when it is coupled to $\mathrm{TiO}_{2}$ which directly transfers photo-generated electrons from the conduction band to interfacial POM possessing empty d orbitals. In this way the rate of conduction band (CB) electron transfer is enhanced in coupled $\mathrm{POM} / \mathrm{TiO}_{2}$ samples, and consequently the charge-pair recombination is delayed [17]. Moreover, by a thermodynamic point of view $\mathrm{PW}_{12} \mathrm{O}_{40}{ }^{3-}$ is a better electron acceptor than $\mathrm{O}_{2}(-0.33$ and $+0.218 \mathrm{~V}$, vs NHE, respectively) [18]. Enhanced degradation of organic compounds in the $\mathrm{UV} / \mathrm{TiO}_{2}$ process has been reported in the presence of Keggin-type POMs, such for instance $\mathrm{H}_{3} \mathrm{PW}_{12} \mathrm{O}_{40}$, supported on $\mathrm{TiO}_{2}$ [19-25].

This work describes the production of 2-propanol from propene and water by using a supported heteropolyacid, denoted as POM, $\left(\mathrm{H}_{3} \mathrm{PW}_{12} \mathrm{O}_{40}\right)$ on $\mathrm{TiO}_{2}$ or $\mathrm{SiO}_{2}$ materials. The cooperative effect of light and heat for the above catalytic reaction has been investigated. The binary $\mathrm{POM} / \mathrm{TiO}_{2}$ material can synergistically take advantage of the POM and of the semiconductor features.

\section{Experimental}

\subsection{Solid samples used as catalysts and photocatalysts}

The solids used as catalysts or photocatalysts were commercial $\mathrm{TiO}_{2}$ (Degussa P25, $50 \mathrm{~m}^{2} \mathrm{~g}^{-1}$ ), $\mathrm{SiO}_{2}$ (Riedel de Haën, $275 \mathrm{~m}^{2} \mathrm{~g}^{-1}$ ) and composites containing $\mathrm{POM}$ and $\mathrm{TiO}_{2}$ or $\mathrm{POM}$ and $\mathrm{SiO}_{2}$. These materials were prepared by impregnation using an aqueous solution containing the adequate amount of the commercial $\mathrm{H}_{3} \mathrm{PW}_{12} \mathrm{O}_{40}$ (Aldrich, $10 \mathrm{~m}^{2} \mathrm{~g}^{-1}$ ) in order to obtain samples with the desired POM weight percentage with respect to the support oxide. Each suspension was kept under constant magnetic stirring at $50^{\circ} \mathrm{C}$ for $1 \mathrm{~h}$, and then evaporated until dryness. The powders used as catalysts and photocatalysts are denoted hereafter as: $15 \% \mathrm{POM} / \mathrm{TiO}_{2}$, $30 \% \mathrm{POM} / \mathrm{TiO}_{2}, 50 \% \mathrm{POM} / \mathrm{TiO}_{2}$ and $70 \% \mathrm{POM} / \mathrm{TiO}_{2}$ for the $\mathrm{POM}$ on $\mathrm{TiO}_{2}$ and $15 \% \mathrm{POM} / \mathrm{SiO}_{2}$ and $50 \% \mathrm{POM} / \mathrm{SiO}_{2}$ for the $\mathrm{POM}$ on $\mathrm{SiO}_{2}$.

\subsection{Characterization of the solids}

Powder X-ray diffraction (PXRD) patterns were obtained by using a Siemens $\mathrm{D}-500$ diffractometer $(\mathrm{Cu} K \alpha$ radiation, $\lambda$ $1.54050 \AA$ ) with quartz as the external standard. BET specific surface areas were measured in a Micromeritics FlowSorb 2300 instrument. Scanning electron microscopy (SEM) was performed using a FEI Quanta 200 ESEM microscope, operating at $20 \mathrm{kV}$ on specimens upon which a thin layer of gold had been evaporated. The diffuse reflectance spectra (DRS) were recorded in air at room temperature in the wavelength range $800-250 \mathrm{~nm}$ using a Shimadzu UV-2401 PC spectrophotometer, with $\mathrm{BaSO}_{4}$ as the reference material. Infrared spectra of the samples in $\mathrm{KBr}$ (Aldrich) pellets were obtained with a FTIR-8400 Shimadzu spectrometer and the spectra were recorded with $4 \mathrm{~cm}^{-1}$ resolution and 256 scans.

\subsection{Reactivity experiments}

A cylindrical continuous Pyrex photoreactor horizontally positioned (diameter: $10 \mathrm{~mm}$, height: $100 \mathrm{~mm}$ ) was used and it operated in gas-solid regime. The set-up of the system is shown in Fig. 1.

A porous glass septum on the inset of the flow allowed to distribute homogeneously the inlet gaseous mixture. The reactivity runs were carried out with $0.5 \mathrm{~g}$ of solid powder by simply dispersing it as a thin layer inside the photoreactor (the fixed bed height was ca. $0.3 \mathrm{~mm}$ ). The gas feeding the photoreactor consisted 


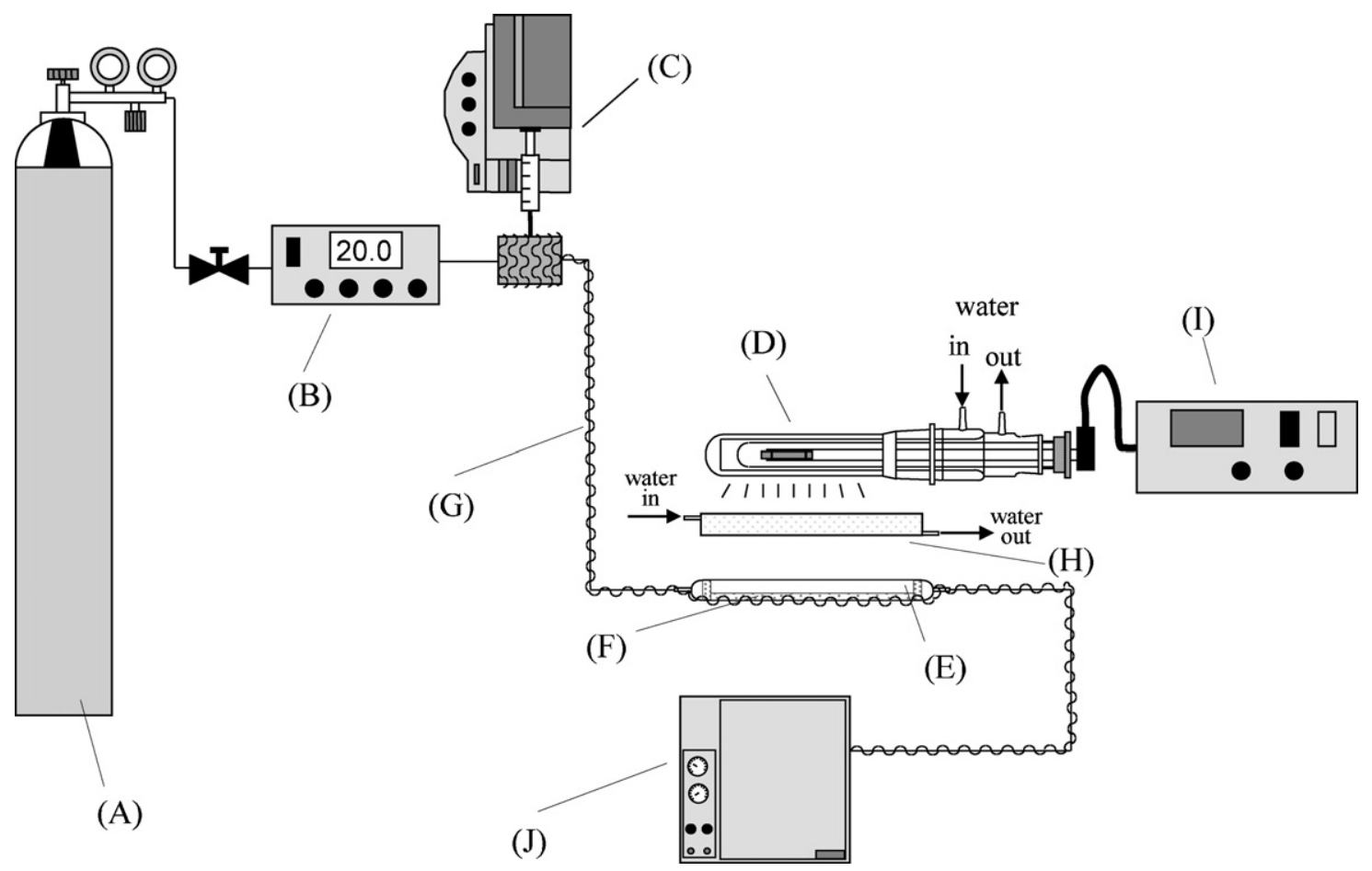

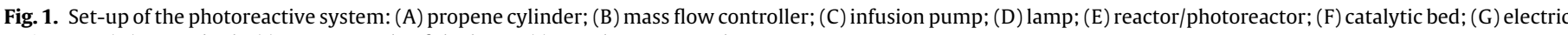
resistance; $(\mathrm{H})$ water bath; $(\mathrm{I})$ power supply of the lamp; $(\mathrm{J})$ gas-chromatograph.

of propene and water with the partial pressures ranging between 72.0-95.6 kPa and $29.3-5.7 \mathrm{kPa}$, respectively. A mass flow controller allowed to feed gaseous propene, whereas water was mixed with the propene stream by means of a home made infusion pump. The flow rate of the gaseous stream for the catalytic and catalytic photo-assisted runs was $20 \mathrm{~cm}^{3} \mathrm{~min}^{-1}$. All the runs were carried out at atmospheric pressure. The reactor and the pipes of the setup to and from the reactor were heated by an electric resistance and K-type thermocouples allowed to monitor the temperature in the whole system. The reactions were performed in the temperature range $50-85^{\circ} \mathrm{C}$. For the catalytic photo-assisted runs the reactor was also illuminated from the top with a Helios-Italquartz $125 \mathrm{~W}$ medium pressure Hg lamp. The temperature inside the (photo)reactor was maintained constant during illumination by means of a refrigeration water jacket surrounding the lamp and a water bath located between the reactor and the lamp filtering the infrared radiations. The irradiance reaching the photoreactor, measured in the range $300-400 \mathrm{~nm}$ with a UVX Digital radiometer, was equal to $1.5 \mathrm{~mW} \mathrm{~cm}^{-2}$. The runs lasted ca. $5 \mathrm{~h}$ and samples of the reacting fluid were analyzed by a HP6890 gas chromatograph equipped with an automatic sampling valve, an Agilent Innowax column and a FID.

\section{Results and discussion}

\subsection{Bulk and textural samples characterization}

The features of the XRD diffraction patters of all the impregnated samples correspond to those of the bare supports (not included for the sake of brevity). No changes in the diffraction patters occurred after the formation of the $\mathrm{POM} / \mathrm{TiO}_{2}$ or $\mathrm{POM} / \mathrm{SiO}_{2}$ binary materials. This indicates that the species deposited are highly dispersed in agreement with previous works [9] and also with our SEM and EDAX observations. Notably the presence of POM induced a decrease of the BET specific surface area $\left(S_{\mathrm{BET}}\right)$ values with respect to the $S_{\mathrm{BET}}$ of the bare supports $\mathrm{TiO}_{2}$ or $\mathrm{SiO}_{2}$. Table 1 includes the $S_{\mathrm{BET}}$ values measured for all of the samples. The higher the amount of POM on the binary material, the lower the surface area of the solid, although the decrease of surface area was not always very significant. In fact, $15 \% \mathrm{POM} / \mathrm{TiO}_{2}\left(44 \mathrm{~m}^{2} \mathrm{~g}^{-1}\right)$ presents a higher specific surface area than 50 or $70 \% \mathrm{POM} / \mathrm{TiO}_{2}\left(38 \mathrm{~m}^{2} \mathrm{~g}^{-1}\right)$ while the figures of $15 \% \mathrm{POM} / \mathrm{SiO}_{2}\left(221 \mathrm{~m}^{2} \mathrm{~g}^{-1}\right)$ and $50 \% \mathrm{POM} / \mathrm{SiO}_{2}\left(220 \mathrm{~m}^{2} \mathrm{~g}^{-1}\right)$ are almost identical. By considering the values of $S_{\mathrm{BET}}$ of the two bare supports $\left(275 \mathrm{~m}^{2} \mathrm{~g}^{-1}\right.$ or $\mathrm{SiO}_{2}$ and $50 \mathrm{~m}^{2} \mathrm{~g}^{-1}$ for $\left.\mathrm{TiO}_{2}\right)$ it can be concluded that the variation of surface area was very small for $\mathrm{POM} / \mathrm{TiO}_{2}$ materials, differently from what found for $\mathrm{POM} / \mathrm{SiO}_{2}$ materials for which the variation was important and virtually independent on the amount of POM. This finding not only indicates the occurrence of a good dispersion of POM on the surfaces of both supports, but also that the smallest amount of POM (15\%) was sufficient to block most of the pores of the large surface area of $\mathrm{SiO}_{2}$. SEM observations reported below are in agreement with these statements.

In fact, observation of the SEM microphotographs, of which selected ones are reported in Fig. 2, indicates that the morphologies of all the $\mathrm{POM} / \mathrm{TiO}_{2}$ samples are very similar to that of the bare $\mathrm{TiO}_{2}$ sample used as support as the agglomerates of these samples present the same shape and consist of nanoparticles with

Table 1

Weight percentage of $\mathrm{W}$ and $\mathrm{Ti}$ (nominal and measured) and specific surface areas (SSA) of the POM supported samples.

\begin{tabular}{|c|c|c|c|c|c|}
\hline \multirow[t]{2}{*}{ Sample } & \multicolumn{2}{|c|}{ W atomic $\%$} & \multicolumn{2}{|c|}{$\mathrm{Ti}$ or $\mathrm{Si}$ atomic \% } & \multirow[t]{2}{*}{$\operatorname{SSA}\left(\mathrm{m}^{2} \mathrm{~g}^{-1}\right)$} \\
\hline & Nominal & EDAX & Nominal & EDAX & \\
\hline $15 \% \mathrm{POM} / \mathrm{TiO}_{2}$ & 4.4 & 5.2 & 95.6 & 94.8 & 44 \\
\hline $30 \% \mathrm{POM} / \mathrm{TiO}_{2}$ & 8.4 & 11 & 91.6 & 89 & 42 \\
\hline $50 \% \mathrm{POM} / \mathrm{TiO}_{2}$ & 13.4 & 16.1 & 86.6 & 83.9 & 38 \\
\hline $70 \% \mathrm{POM} / \mathrm{TiO}_{2}$ & 17.7 & 18 & 82.3 & 82 & 38 \\
\hline $15 \% \mathrm{POM} / \mathrm{SiO}_{2}$ & 3.4 & 3.8 & 96.6 & 96.2 & 221 \\
\hline $50 \% \mathrm{POM} / \mathrm{SiO}_{2}$ & 10.4 & 10.8 & 89.6 & 89.2 & 220 \\
\hline $\mathrm{TiO}_{2}$ Degussa P25 & - & - & - & - & 50 \\
\hline $\mathrm{SiO}_{2}$ Riedel & - & - & - & - & 275 \\
\hline Bare POM & - & - & - & - & 15 \\
\hline
\end{tabular}



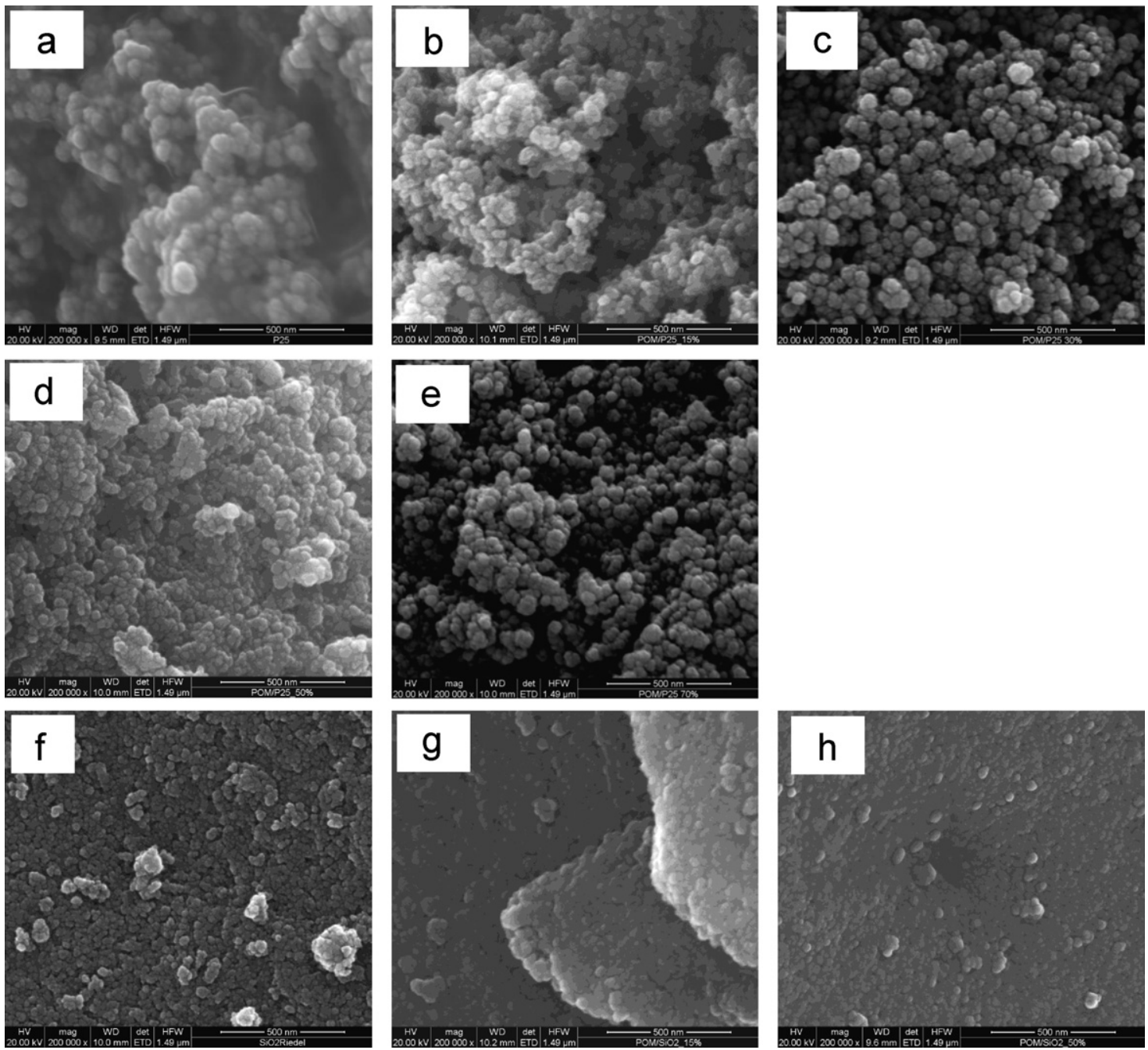

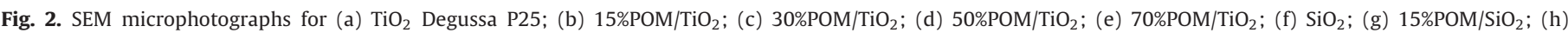
$50 \% \mathrm{POM} / \mathrm{SiO}_{2}$.

similar sizes (ca. 30-40 nm, evaluated by observing microphotographs at higher magnification, not reported for the sake of brevity) (Fig. 2(a)-(e)). On the contrary it can be observed a slight enlargement of the nanoparticles constituting the agglomerates for both $15 \%$ and $50 \% \mathrm{POM} / \mathrm{SiO}_{2}$ samples. In this case, the size of nanoparticles increased from ca. $20 \mathrm{~nm}$ for the bare $\mathrm{SiO}_{2}$ to ca. $30 \mathrm{~nm}$ for the impregnated samples (Fig. 2(f)-(h)). The interstitial spaces between the bare $\mathrm{SiO}_{2}$ particles almost disappeared already when $15 \%$ of POM was deposited onto the surface (Fig. 2(g)) and this could explain the surface area decrease for the $\mathrm{POM} / \mathrm{SiO}_{2}$ materials with respect to the bare $\mathrm{SiO}_{2}$.

Moreover a quite homogeneous distribution of POM on the surface of $\mathrm{TiO}_{2}$ and $\mathrm{SiO}_{2}$ was confirmed by EDAX analyses that indicated also that no significant area on the surface of the supports remained uncovered by POM. The amount of POM present resulted almost equal to the nominal weight ratio POM:support for all the samples. Table 1 reports the nominal values of atomic percentage of $\mathrm{W}, \mathrm{Ti}$ and $\mathrm{Si}$ and the values experimentally determined by EDAX, by taking into account in the calculation the presence of thirteen water molecules of crystallization in the POM molecule [26]. During the analysis work few exceptions were noted for some particles of the $50 \% \mathrm{POM} / \mathrm{SiO}_{2}$ sample that resulted poorer or richer in POM content with respect to the nominal value. $\mathrm{W}$ atomic percentage was in the range $2.4 \%$ and $17.4 \%$, but the average of these two values is almost equal to the nominal one, i.e. $10.4 \%$.
Diffuse reflectance UV-vis spectra (DRS) of bare $\mathrm{TiO}_{2}$, commercial POM, and selected $\mathrm{POM} / \mathrm{TiO}_{2}$ samples are reported in Fig. 3(A), while those of bare $\mathrm{SiO}_{2}$, commercial POM, and $\mathrm{POM} / \mathrm{SiO}_{2}$ samples are reported in Fig. 3(B).

In Fig. 3(A) all samples exhibit the absorption edges typical of the semiconductor materials. It can be identified the charge transfer process from $\mathrm{O} 2 \mathrm{p}$ to $\mathrm{Ti} 3 \mathrm{~d}$ ascribed to the band gap of $\mathrm{TiO}_{2}$ semiconductor and the ligand to metal charge transfer $\mathrm{O} 2 \mathrm{p}$ to W $5 \mathrm{~d}$ occurring in the $\mathrm{H}_{3} \mathrm{PW}_{12} \mathrm{O}_{40}$ sample. A slight decrease of reflectance, i.e. increase of absorbance, can be observed in the visible region by adding the POM to the bare $\mathrm{TiO}_{2}$. This absorbance could be due to the textural properties of the sample. On the other hand, the position of the band edge suffers a shift to higher wavelength in the $15 \% \mathrm{POM} / \mathrm{TiO}_{2}$ and $50 \% \mathrm{POM} / \mathrm{TiO}_{2}$ in respect to both bare $\mathrm{TiO}_{2}$ and POM. This shift can be ascribed to some modifications of the coordination environment of some species onto $\mathrm{TiO}_{2}$ surface of the loaded samples as observed before [25]. A new conduction band with a lower energy level formed with the contribution of $\mathrm{Ti}$ $3 \mathrm{~d}$ and $\mathrm{W} 5 \mathrm{~d}$ orbitals, due to their similar energy, was observed in a $\mathrm{POM} / \mathrm{TiO}_{2}$ composite prepared by an hydrothermal methodology [27], where the absorption spectrum shows a band at lower energies with respect to both $\mathrm{TiO}_{2}$ and $\mathrm{POM}$. Nevertheless, a perusal of the absorption spectra of our solid samples, reported in the inset of Fig. 3(A) excludes this possibility. In the absorbance spectra, inset of Fig. $3(\mathrm{~A}), \mathrm{TiO}_{2}$ presents a strong absorption in the range 

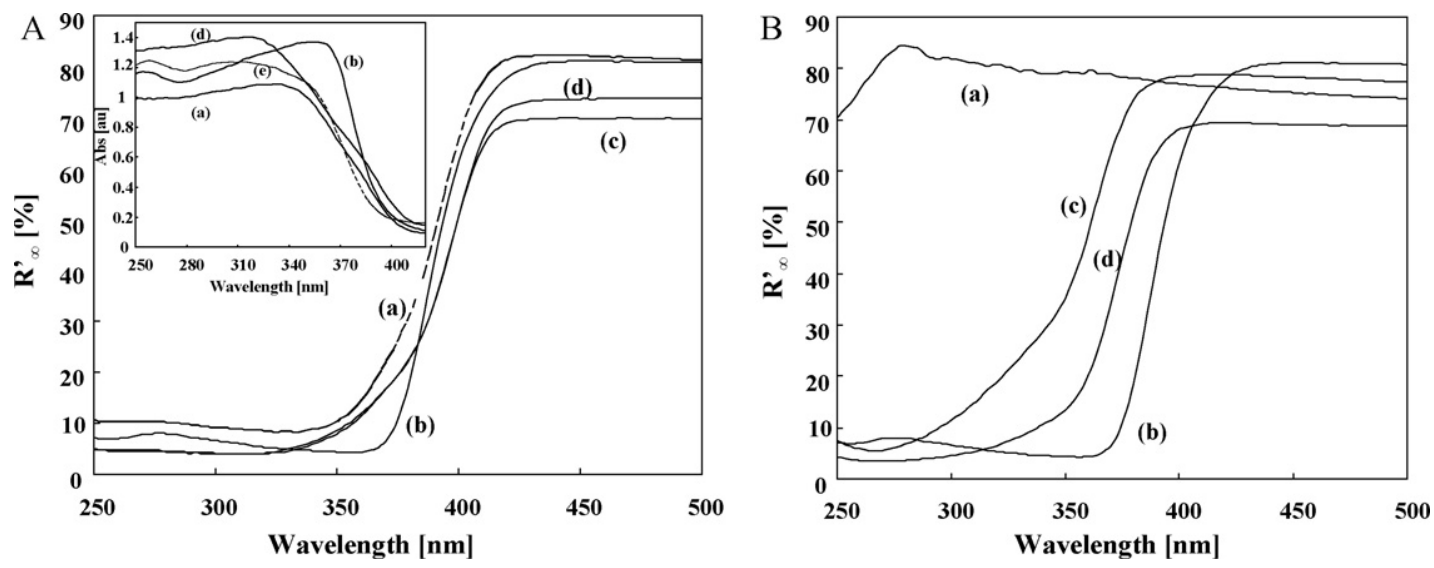

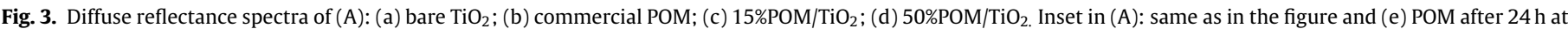
$100{ }^{\circ} \mathrm{C}$. (B): (a) bare $\mathrm{SiO}_{2}$; (b) commercial POM; (c) $15 \% \mathrm{POM} / \mathrm{SiO}_{2}$; (d) $50 \% \mathrm{POM} / \mathrm{SiO}_{2}$.

200-380 nm, ascribed to the electron excitation from the valence band to the conduction band as above mentioned (transition of $\mathrm{O}$ $2 \mathrm{p}$ to $\mathrm{Ti} 3 \mathrm{~d}$ ) corresponding to its band gap, ca. $3.2 \mathrm{eV}$. The commercial POM showed a strong UV absorption attributed to the charge transfer from $\mathrm{O} 2 \mathrm{p}$ to $\mathrm{W} 5 \mathrm{~d}$ which occurred at the $\mathrm{W}=\mathrm{O}$ bonds of the Keggin unit at ca. $190 \mathrm{~nm}$ (not shown) and a weaker band at approximately $260 \mathrm{~nm}$ corresponding to a charge transfer in the $\mathrm{W}-\mathrm{O}-\mathrm{W}$ bonds of the units [13]. Moreover a wide band can be observed in the range $300-360 \mathrm{~nm}$, in agreement with the studies by Pizzio et al. [9]. This wide band, observed only for the optical characterization of the solid POM material, is responsible for the location of the band edge of the bare POM in Fig. 3(A) at wavelengths higher than expected. It is worth nothing that this absorption wide band is partially reduced and shifted to higher energies when the bare POM was annealed at $100^{\circ} \mathrm{C}$, evidencing the role played by water on the solid POM. In Fig. 3(A) inset it can be observed also that the sample $50 \% \mathrm{POM} / \mathrm{TiO}_{2}$ showed a negligible shift in the charge transfer band compared to the starting $\mathrm{TiO}_{2}$, i.e. the absorption threshold almost did not change, suggesting that POM did not influence the electronic properties of the bare $\mathrm{TiO}_{2}$. DRS spectra of $\mathrm{POM} / \mathrm{SiO}_{2}$ samples reported in Fig. 3(B) show absorption edges that can be ascribed to $\mathrm{POM}$ and that are, analogously to the $\mathrm{POM} / \mathrm{TiO}_{2}$ material, shifted to higher wavelengths by increasing the POM amount.

The samples were also analyzed by FTIR in order to confirm the structural integrity of the Keggin unit after the deposition onto the support. The structure of the $\mathrm{PW}_{12} \mathrm{O}_{40}{ }^{3-}$ anion consists of a $\mathrm{PO}_{4}$ tetrahedron surrounded by four $\mathrm{W}_{3} \mathrm{O}_{9}$ groups formed by edge sharing octhaedra. These groups are connected each other by corners sharing oxygen atoms [28]. This arrangement gives rise to four stretching bands between 1100 and $700 \mathrm{~cm}^{-1}$. It is difficult to characterize the structures of the composites with IR spectroscopy, due to the presence of the $\mathrm{TiO}_{2}$ cut-off (intense and broad vibration peaks originated from $\mathrm{Ti}-\mathrm{O}-\mathrm{Ti}$ bonds) located at wavenumbers lower than $900 \mathrm{~cm}^{-1}$. Also in the $\mathrm{POM} / \mathrm{SiO}_{2}$ samples some bands appear overlapped with the bands of the support.

Fig. 4 shows the FTIR spectra of the $15 \% \mathrm{POM} / \mathrm{TiO}_{2}$, $30 \% \mathrm{POM} / \mathrm{TiO}_{2}, \quad 50 \% \mathrm{POM} / \mathrm{TiO}_{2} \quad 70 \% \mathrm{POM} / \mathrm{TiO}_{2}$ and $50 \% \mathrm{POM} / \mathrm{SiO}_{2}$ samples along with both the bare $\mathrm{POM}$ and $\mathrm{SiO}_{2}$. Four main stretching vibrations of the skeletal bonds in POM are located at $\mathrm{ca}$. the same wavenumbers for the commercial POM and also when the POM is loaded on the surface of both $\mathrm{TiO}_{2}$ and $\mathrm{SiO}_{2}$ materials, indicating that the Keggin geometry of POM has been still preserved in the binary material. The typical band for $\mathrm{P}-\mathrm{O}$ stretching mode $\left(1080 \mathrm{~cm}^{-1}\right)$ is displayed, along with the $\mathrm{W}=0$ stretching $\left(990 \mathrm{~cm}^{-1}\right)$. The two peaks at ca. $910 \mathrm{~cm}^{-1}$ and $810 \mathrm{~cm}^{-1}$ [29], attributed to two types of $\mathrm{W}-\mathrm{O}-\mathrm{W}$ units are partially covered by the cut-off of the $\mathrm{TiO}_{2}$ in the $\mathrm{POM} / \mathrm{TiO}_{2}$ samples (Fig. 4(b)). The
$\mathrm{SiO}_{2}$ asymmetric and symmetric $\mathrm{Si}-\mathrm{O}-\mathrm{Si}$ stretching vibrations band located at ca. $1080 \mathrm{~cm}^{-1}$ and $800 \mathrm{~cm}^{-1}$ [30], respectively completely overlap two fingerprint vibrations of the $\mathrm{PW}_{12} \mathrm{O}_{40}{ }^{-3}$ species in the range $1100-700 \mathrm{~cm}^{-1}$; however the $\mathrm{W}=0$ stretching vibration at ca. $981 \mathrm{~cm}^{-1}$ remains the same for all of the samples. Therefore, the spectra indicated that the species present in the samples correspond to the commercial POM anion $\mathrm{PW}_{12} \mathrm{O}_{40}{ }^{3-}$ in agreement with the literature [9]. It is notable that the bands attributed to the Keggin's unit skeletal vibrations did not become more intense in the samples where the POM was supported with respect to those attributed to the bare POM, as expected in the absence of anion-anion interactions. This finding can be explained by considering the relative low amount of POM and/or its

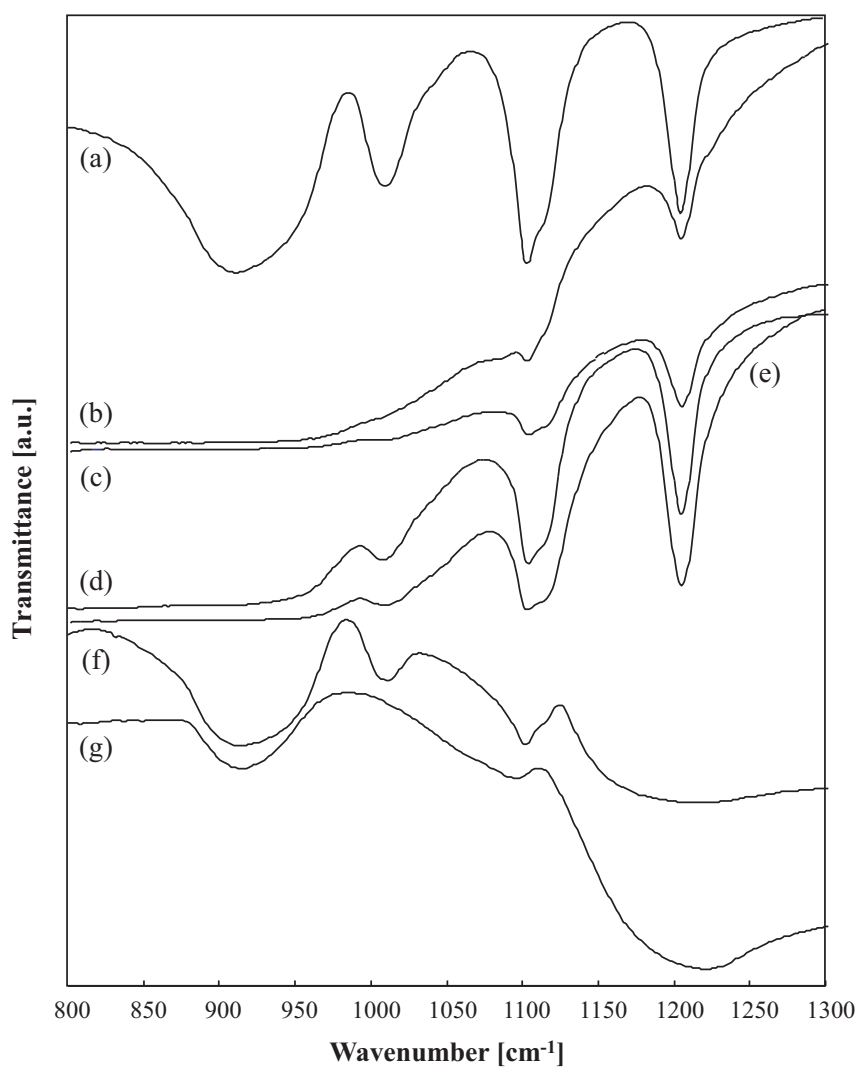

Fig. 4. FTIR spectra of $\mathrm{KBr}$ pellets of: (a) commercial $\mathrm{H}_{3} \mathrm{PW}_{12} \mathrm{O}_{40}$; (b) $15 \% \mathrm{POM} / \mathrm{TiO}_{2}$; (c) $30 \% \mathrm{POM} / \mathrm{TiO}_{2}$; (d) $50 \% \mathrm{POM} / \mathrm{TiO}_{2}$; (e) $70 \% \mathrm{POM} / \mathrm{TiO}_{2}$; (f) $50 \% \mathrm{POM} / \mathrm{SiO}_{2}$; (g) commercial bare $\mathrm{SiO}_{2}$. 


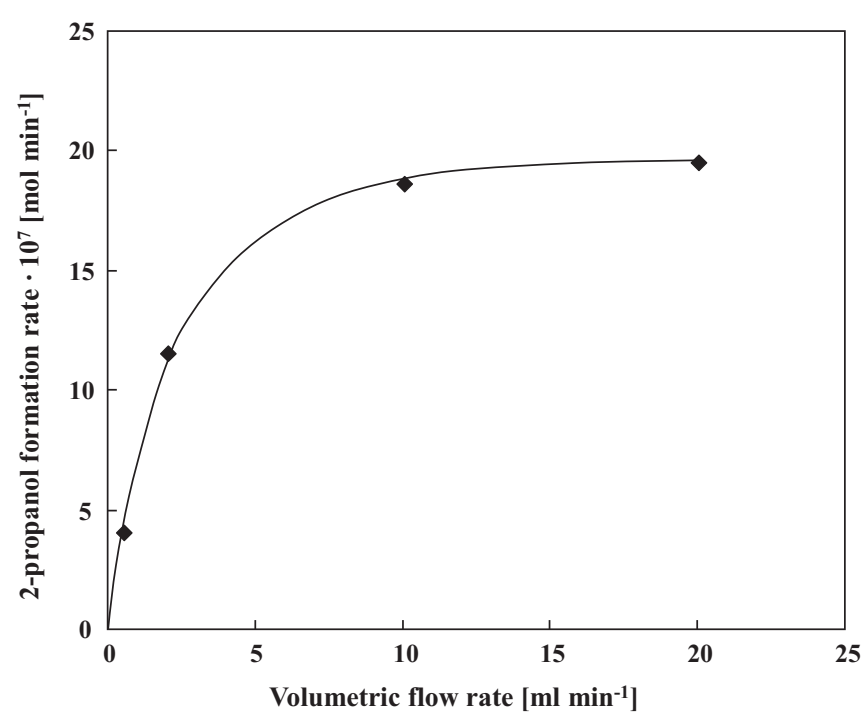

Fig. 5. 2-propanol formation rate versus gas flow volumetric rate. Catalytic run in the presence of $0.5 \mathrm{~g}$ of $15 \% \mathrm{POM} / \mathrm{TiO}_{2}$, temperature $85^{\circ} \mathrm{C}$, water partial pressure $5.7 \mathrm{kPa}$.

homogeneous dispersion onto the support surface [29]. H-bonding interactions cannot be excluded, considering the slight broadening of the bands indicating that the vibrations could be disturbed by dipole-dipole interactions [30], probably between the Keggin units and the $\mathrm{TiO}_{2}$ or $\mathrm{SiO}_{2}$ surface [31].

It is worth noting that samples containing $15 \% \mathrm{POM} / \mathrm{TiO}_{2}$ and $15 \% \mathrm{POM} / \mathrm{SiO}_{2}$ showed the bands of the main skeletal POM bands in the same position of the 30,50 and $70 \% \mathrm{POM} / \mathrm{TiO}_{2}$ supported materials, indicating that the interaction between POM and the support does not change significantly. Moreover, the analogous FTIR spectra of the $\mathrm{POM} / \mathrm{TiO}_{2}$ materials after being used $10 \mathrm{~h}$ in catalytic or catalytic photo-assisted reactions, not reported for the sake of brevity, showed no significant differences, in the range $1200-800 \mathrm{~cm}^{-1}$, with respect to the fresh powders indicating that no modifications of the POM Keggin unit occurred after the reactivity.

\subsection{Reactivity experiments}

No reactivity was observed in the presence of both bare $\mathrm{SiO}_{2}$ and $\mathrm{TiO}_{2}$ samples under the same experimental conditions used for the catalytic and catalytic photo-assisted runs. Consequently it can be concluded that the presence of POM is needed for the occurrence of propene hydration process.

Fig. 5 reports 2-propanol formation rate versus gas flow rate for a selected catalytic run carried out in the presence of the $15 \% \mathrm{POM} / \mathrm{TiO}_{2}$ sample. An enhancement of the reaction rate may be observed for flow rates up to $\mathrm{ca} .10 \mathrm{~cm}^{3} \mathrm{~min}^{-1}$, for higher values the reaction rate did not change significantly. This finding indicates that mass transfer resistance limits the reaction rate for flows lower than $10 \mathrm{~cm}^{3} \mathrm{~min}^{-1}$. On this ground the flow rate of the gaseous stream was chosen equal to $20 \mathrm{~cm}^{3} \mathrm{~min}^{-1}$ both for the catalytic and catalytic photo-assisted runs. Time needed to reach steady state conditions was ca. $1 \mathrm{~h}$ in all cases, both in the absence and in the presence of light. Anyway we have followed each run for additional $4 \mathrm{~h}$, observing no modification in the reactivity. Moreover, selected runs were also carried out for $10 \mathrm{~h}$ observing that no deactivation of the catalysts occurred. Throughout all the runs carried out in the presence of $\mathrm{POM} / \mathrm{SiO}_{2}$ or $\mathrm{POM} / \mathrm{TiO}_{2}$ samples the appearance of 2 propanol was observed as the main product. Traces of propanone were only found in the presence of light while traces of di-isopropyl ether were found during both catalytic and photo-assisted catalytic experiments.
Fig. 6 reports formation rate of 2-propanol versus reaction temperature in catalytic (A) and catalytic photo-assisted (B) reactions by using bare $\mathrm{POM}$ and $\mathrm{POM}$ supported $\mathrm{TiO}_{2}$ materials. From the observation of Fig. 6, the reactivity increased by increasing the reaction temperature and it was always, at any temperature, higher in the presence of UV light. Moreover, the reactivity in both catalytic and catalytic photo-assisted systems increased by increasing the amount of the supported POM content up to an amount of $50 \%$; indeed, the $70 \% \mathrm{POM} / \mathrm{TiO}_{2}$ resulted slightly less active than the $50 \% \mathrm{POM} / \mathrm{TiO}_{2}$ sample but its activity was higher than that showed by the $30 \% \mathrm{POM} / \mathrm{TiO}_{2}, 15 \% \mathrm{POM} / \mathrm{TiO}_{2}$ and bare POM. It is worth noting that the reactivity of bare POM was much lower than that of the POM/supported materials, both in the absence and in the presence of UV light. Consequently, it seems that there is an optimum in the supported POM amount that, in this work, corresponds to $50 \% \mathrm{POM} / \mathrm{TiO}_{2}$. The interaction of the POM with the support seems fundamental for the increase of the reactivity. This interaction gave a major contribution to the reactivity up to $50 \%$ supported POM. This contribution slightly decreased for higher amounts of POM, probably due to the higher POM coverage of the support surface. In other words it seems that the role played by the support is more evident for the powders with POM content lower than $70 \%$. By increasing the supported POM amount the reactivity increased until a certain point; in fact, as reported by Misono et al. [5] POM can interact with the support at lower loading levels giving rise to a possible role of the support in the reaction or by modifying the chemical-physical features of the POM. It can be concluded, in agreement with the literature [1], that the support plays a minor role when the powders with the highest POM content are used, because the properties of bulk POM prevail.

In order to study the influence of the support, Fig. 7(A) and (B) report a comparison of the reactivity observed for POM samples supported on $\mathrm{TiO}_{2}$ and on $\mathrm{SiO}_{2}$. In particular, Fig. 7(A) reports formation rate of 2-propanol versus reaction temperature in catalytic and catalytic photo-assisted reactions by using the materials with the lowest POM content. Both in the presence and in the absence of UV radiation the $15 \% \mathrm{POM} / \mathrm{SiO}_{2}$ showed a lower activity than $15 \% \mathrm{POM} / \mathrm{TiO}_{2}$. In any case, reaction rate increased by increasing the reaction temperature. As far as the $15 \% \mathrm{POM} / \mathrm{TiO}_{2}$ sample is concerned, the reaction rate improved 3.7 times at $50^{\circ} \mathrm{C}$ and 1.5 times at $85^{\circ} \mathrm{C}$, in the presence of irradiation. With the $15 \% \mathrm{POM} / \mathrm{SiO}_{2}$ no difference was observed between the catalytic and the catalytic photo-assisted reaction rates up to ca. $65^{\circ} \mathrm{C}$, whereas an improvement of ca. 1.4 times was observed at $85^{\circ} \mathrm{C}$.

Fig. 7(B) reports formation rate of 2-propanol versus reaction temperature by using the powders with the highest POM content. The general trend by using these materials is that the catalytic photo-assisted reaction is faster than the catalytic one. At $85^{\circ} \mathrm{C}$ the catalytic photo-assisted reaction is 1.3 or 1.2 times faster than the catalytic one by using $50 \% \mathrm{POM} / \mathrm{TiO}_{2}$ and $50 \% \mathrm{POM} / \mathrm{SiO}_{2}$, respectively. At $70^{\circ} \mathrm{C}$ the catalytic reaction is 1.5 times faster by using $50 \% \mathrm{POM} / \mathrm{TiO}_{2}$ than by using $50 \% \mathrm{POM} / \mathrm{SiO}_{2}$ sample, but the difference in the catalytic reaction rate appears negligible at $85^{\circ} \mathrm{C}$. As far as the catalytic photo-assisted reaction is concerned, the reaction rate at $85^{\circ} \mathrm{C}$ is 1.2 times higher for $50 \% \mathrm{POM} / \mathrm{TiO}_{2}$ with respect to $50 \% \mathrm{POM} / \mathrm{SiO}_{2}$ sample. In the presence of light the reactivity was always higher both for the materials based on $\mathrm{TiO}_{2}$ and $\mathrm{SiO}_{2}$, but those based on $\mathrm{TiO}_{2}$ showed to be more active than those based on $\mathrm{SiO}_{2}$. Consequently the interaction between $\mathrm{TiO}_{2}$ and $\mathrm{POM}$ is more effective than the interaction between $\mathrm{SiO}_{2}$ and $\mathrm{POM}$ giving rise to a better catalytic activity both in the absence and in the presence of light.

It is worth noting that the difference in the reactivity observed between the $\mathrm{POM} / \mathrm{TiO}_{2}$ and $\mathrm{POM} / \mathrm{SiO}_{2}$ samples, both in the 

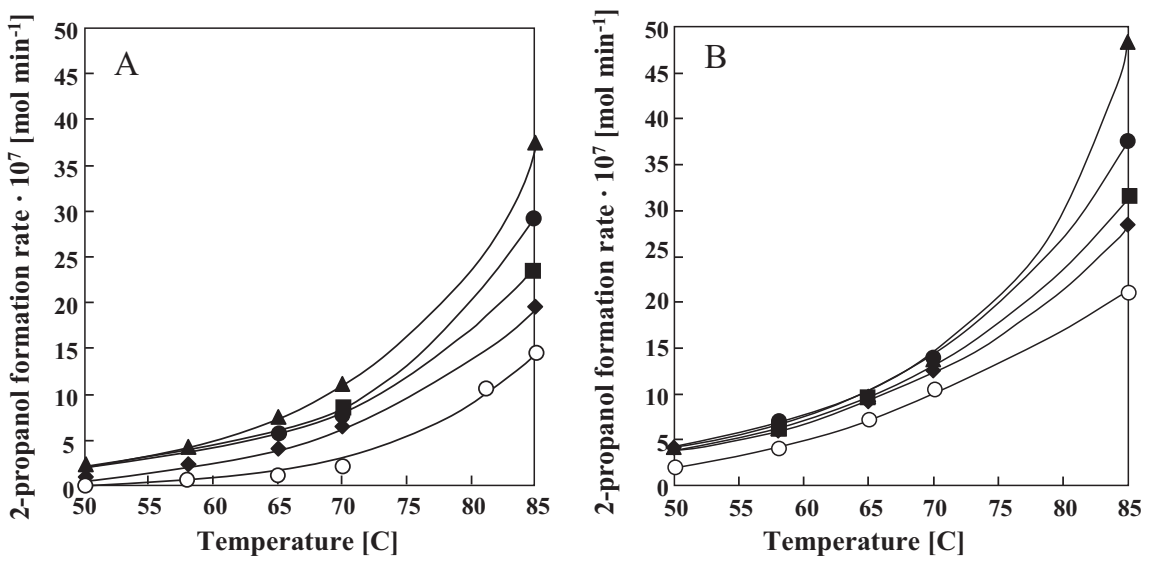

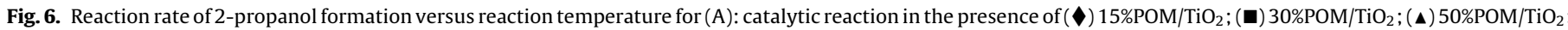

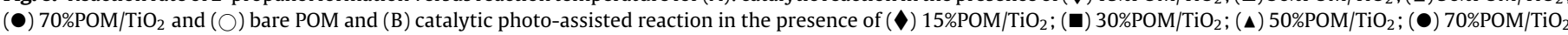
and $(\bigcirc)$ bare POM. $0.5 \mathrm{~g}$ of solid material, gas flow volumetric rate $20 \mathrm{ml} \mathrm{min}^{-1}$, water and propene partial pressure $5.7 \mathrm{kPa}$ and $95.6 \mathrm{kPa}$, respectively.
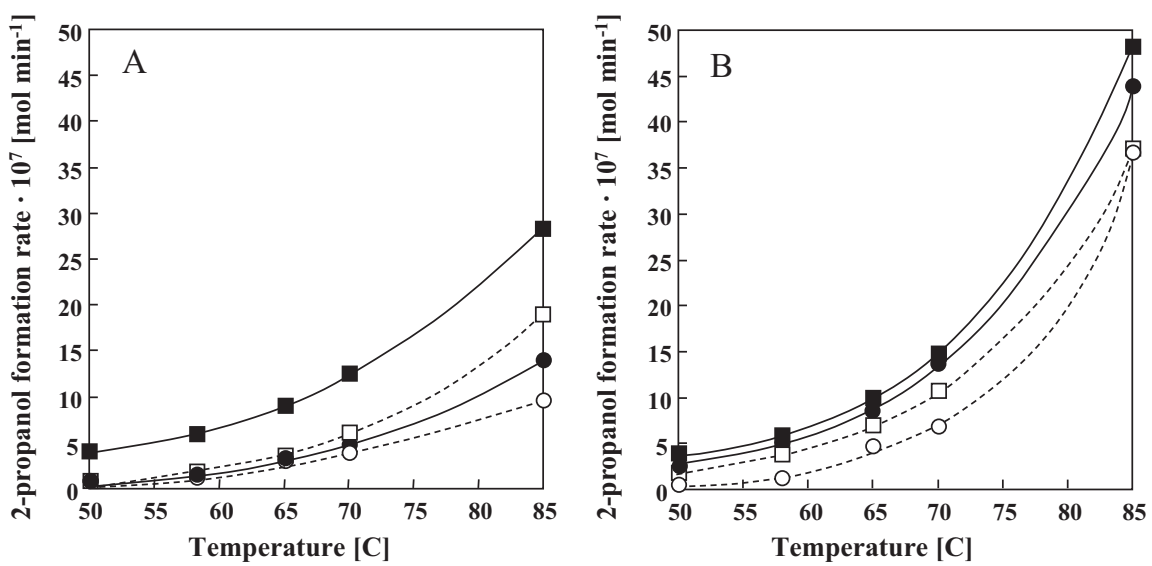

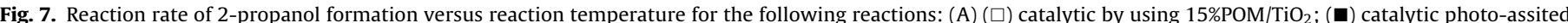

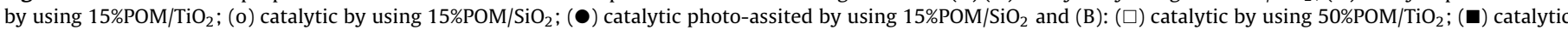

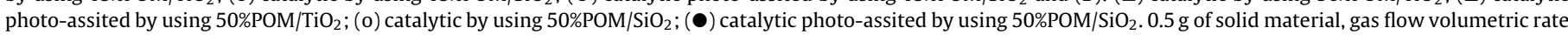
$20 \mathrm{ml} \mathrm{min}^{-1}$, water and propene partial pressure $5.7 \mathrm{kPa}$ and $95.6 \mathrm{kPa}$, respectively.

presence and in the absence of light, was less significant for the materials with the highest amount of POM. This finding suggests that for the samples containing the highest POM amount, the last played a shield effect hindering $\mathrm{TiO}_{2}$ to give an important contribution to the reactivity because the $\mathrm{TiO}_{2}$ surface remained almost completely covered. By increasing the POM amount in the catalyst the reactivity increased by using both the samples based on $\mathrm{SiO}_{2}$ and $\mathrm{TiO}_{2}$, and this suggests that POM is the phase playing the major role in the formation of 2-propanol. The reactivity increased by increasing the reaction temperature, as reported in literature for the catalytic reaction carried out in the range of temperatures studied [8], but in all cases the reactivity in the presence of light was always higher.
Reaction Scheme 1 shows the hypothesized mechanism of the catalytic hydration of propene to form 2-propanol, and it is supported by the insights already reported by Ivanov et al. [8]. This reaction occurs in the contemporary presence of heat and the solid $\mathrm{POM} / \mathrm{TiO}_{2}$ or $\mathrm{POM} / \mathrm{SiO}_{2}$. It is important to underline that, as demonstrated by Mizuno and Misono [5], POM has a discrete and mobile ionic structure. It can retain in the bulk a large amount of polar water molecules possessing a very high proton mobility. Consequently the catalytic reaction occurs not only at the surface but also in the crystalline bulk of the supported POM that behaves as a highly concentrated solution. Proton on the POM surface is coordinated by two water molecules forming the di-aqua-proton species dioxonium, $\mathrm{H}_{5} \mathrm{O}_{2}{ }^{+}$[26], and these species form bridges between the

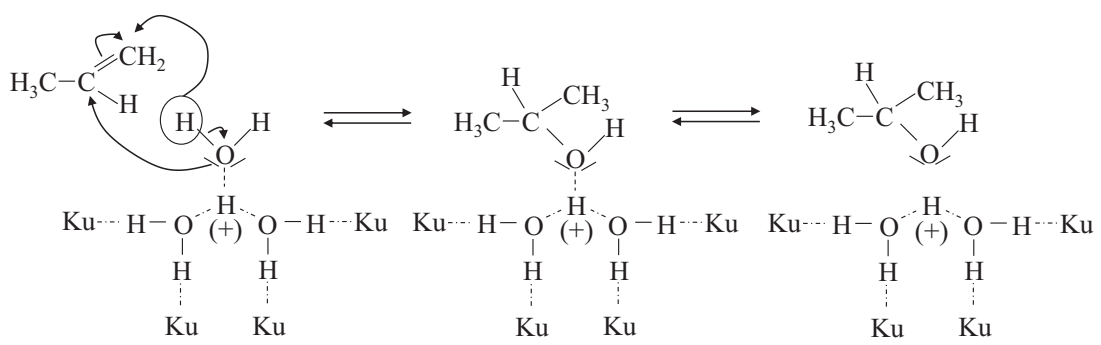

Scheme 1. Proposed reaction pathway for the catalytic propene hydration to obtain 2-propanol in the presence of the supported POM. 
a
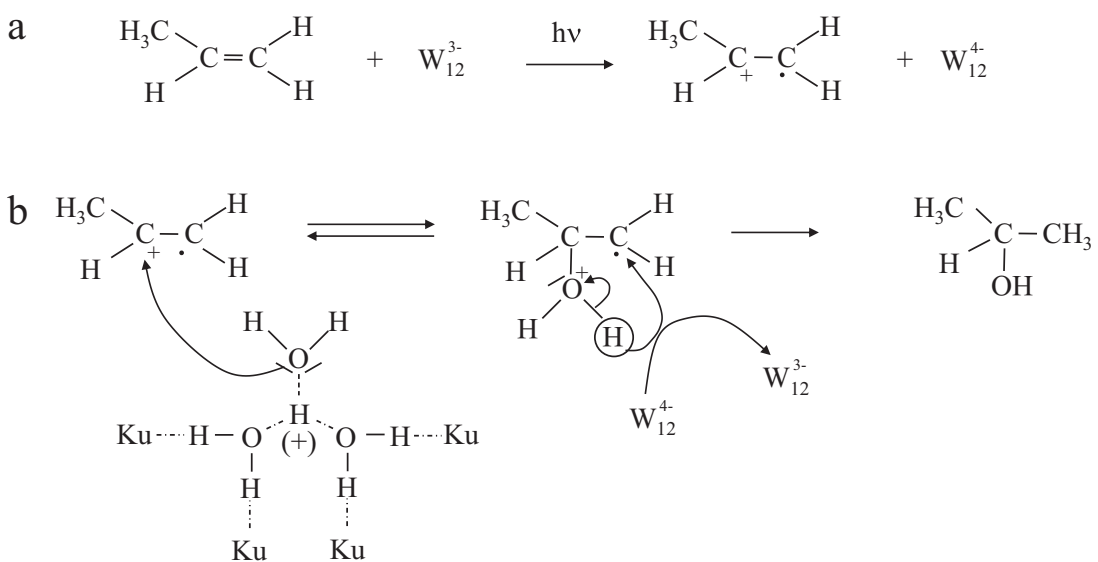

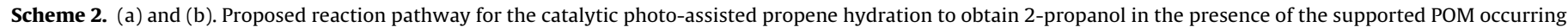
along with the catalytic reaction.

Keggin ions units, represented as $\mathrm{Ku}$ in the Scheme 1. According to Ivanov et al. the role of active centres in the catalytic reaction is played by $\mathrm{H}_{5} \mathrm{O}_{2}{ }^{+}$. The $\mathrm{H}_{5} \mathrm{O}_{2}{ }^{+}$sites contribute to stabilize the polar water molecules with formation of the so-called "pseudo-liquid" phase.

Consequently the reaction occurs between propene from the gas phase and dioxonium ions situated between Keggin anions. A direct correlation between the reactivity and the acidity of the surface in terms of amount of $\mathrm{H}_{5} \mathrm{O}_{2}{ }^{+}$is the key factor to obtain a maximum activity [8]. Stabilization of intermediates due to the presence of $\mathrm{H}_{5} \mathrm{O}_{2}{ }^{+}$can explain also the difference in the behaviour of $15 \%$ and $50 \% \mathrm{POM} / \mathrm{TiO}_{2}$ or $\mathrm{POM} / \mathrm{SiO}_{2}$, due to the likely modification of the acid strength that increases with the POM amount. These results are consistent with those obtained before by using $\mathrm{SiO}_{2}$ as support for low and high loaded POM binary materials [8]. On the other hand, by changing the support the physico-chemical features of POM change [5] and this can explain the higher catalytic activity of $\mathrm{POM} / \mathrm{TiO}_{2}$ with respect to $\mathrm{POM} / \mathrm{SiO}_{2}$.

As far as the catalytic photo-assisted reactions are concerned, in addition to the reaction pathway described in Scheme 1, a further key role is played by POM that is photosensitized upon exposure to near UV light. The ground state of POM, represented in reaction (1) as $\mathrm{W}_{12}{ }^{3-}$, is excited by the near-UV light transforming into an excited species $\left(\mathrm{W}_{12}{ }^{3-{ }^{*}}\right)$. The last has a strong oxidation power and can receive an electron from the substrate being reduced to a blue species $\left(\mathrm{W}_{12}{ }^{4-}\right)$ [14]. Notably the blue colour of the supported POM is visible in our system:

$\mathrm{W}_{12}^{3-} \stackrel{\mathrm{hv}}{\longrightarrow} \mathrm{W}_{12}^{3-*}$

$\mathrm{W}_{12}^{3-*}+e^{-} \rightarrow \mathrm{W}_{12}^{4-}$

Scheme 2 reports the above hypothesized pathway for the hydration reaction in the contemporary presence of the POM hydrated surface, near-UV light and heat, without the contribution of the $\mathrm{TiO}_{2}$ semiconductor. Scheme 2(a) represents the role played by the photoexcited POM, a very oxidant species that can abstract an electron from the double bond of propene. In Scheme 2(b) it can be noticed that the $\mathrm{H}_{2} \mathrm{O}_{5}{ }^{+}$species play the same role than in the catalytic reaction (see Scheme 1). Propene carbocation coordinates a water molecule from the dioxonium species, hence transferring the positive charge on the oxygen atom. In the showed mechanism the $\mathrm{W}_{12}{ }^{4-}\left(\mathrm{POM}^{-}\right)$is re-oxidized to the starting $\mathrm{W}_{12}{ }^{3-}$ (POM) species while one proton is reduced forming a bond with a carbon of the produced propanol. The step in which $\mathrm{H}^{+}$re-oxidizes $\mathrm{POM}^{-}$species to POM has been already reported and it seems to be $100 \%$ efficient [14].

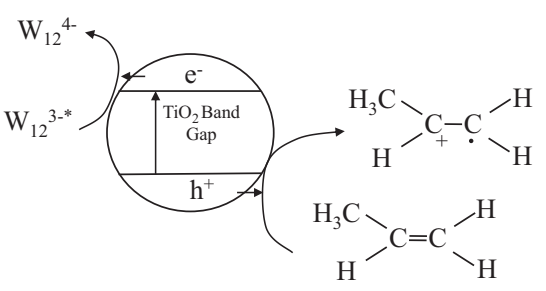

Scheme 3. Synergistic effect between the POM molecule and $\mathrm{TiO}_{2}$ in the $\mathrm{POM} / \mathrm{TiO}_{2}$ composite for the catalytic photo-assisted propene hydration.

A synergistic effect occurs in the system where $\mathrm{TiO}_{2}$ crystalline particles are present along with the hydrated POM Keggin units. Scheme 3 represents the hypothesized reaction pathway for the hydration reaction. Reactions (1) occurs in the presence of the nearUV light and the photoexcited POM $\left(\mathrm{W}_{12}{ }^{3-^{*}}\right)$ possesses a strong oxidation power $\left(E^{\circ}{ }_{\mathrm{POM} / \mathrm{POM}^{-}}=+0.22 \mathrm{~V}\right.$ vs. NHE [32], sufficient to abstract a photogenerated (by UV-light) electron from the conduction band of $\mathrm{TiO}_{2}(-0.22 \mathrm{~V}$ vs. NHE at $\mathrm{pH} 1.95)$ [12]. Such an electron transfer could play two roles: (i) produces a higher number of $\left(\mathrm{W}_{12}{ }^{4-}\right)$ species inducing an increase of the reaction rate of 2-propanol formation and (ii) can inhibit the fast electron-hole recombination on $\mathrm{TiO}_{2}$. In the last case the trapped holes have sufficient time to react with propene molecule to generate radicals that can evolve on the surface of the supported POM as reported in Scheme 2(b). $\mathrm{W}_{12}{ }^{4-}$ transfers the electron to propene carbocation coordinated to the water molecule (see Scheme 2(b)) to form 2-propanol. The proposed mechanism is virtually identical to that proposed by Yoon et al. [20].

\section{Conclusions}

The hydration of propene to obtain 2-propanol occurred successfully in gas-solid regime at atmospheric pressure and at temperatures in the range $50-85^{\circ} \mathrm{C}$ by using both $\mathrm{POM} / \mathrm{TiO}_{2}$ and $\mathrm{POM} / \mathrm{SiO}_{2}$ materials. In any case the reactivity increased by increasing the reaction temperature and it was always, at any temperature, higher for the catalytic photo-assisted reaction than for the catalytic reaction. Moreover, the reactivity of the $\mathrm{POM} / \mathrm{TiO}_{2}$ samples increased by increasing the amount of the supported POM content up to an amount of $50 \%$, both in the absence and in the presence of UV light.

The contemporary presence of heat and UV light improved the activity of the $15 \% \mathrm{POM} / \mathrm{TiO}_{2}$ solid with respect to $15 \% \mathrm{POM} / \mathrm{SiO}_{2}$. In the last case the $\mathrm{POM} / \mathrm{TiO}_{2}$ materials showed higher catalytic and catalytic photo-assisted activity than $\mathrm{POM} / \mathrm{SiO}_{2}$. Both solids 
with the 50\% weight of POM showed a higher performance in the presence of UV light with respect to the bare supports. POM species played the key role in both the catalytic and photo-assisted catalytic reactions, due to its surface acidity and ability to form strong oxidant species under UV irradiation. The presence of $\mathrm{TiO}_{2}$ under UV irradiation improved the POM performance supplying conduction band electrons.

\section{Acknowledgements}

The authors wish to thank MIUR (Rome) and Università degli Studi di Palermo for financial support.

\section{References}

[1] G. Ertl, H. Knözinger, J. Weitkamp, Handbook of Heterogeneous Catalysis, Wiley Vch Verlag Gmbh, Weinheim, 2008.

[2] K. Tao, W. Li, H. Li, X. Qi, Appl. Catal. A: Gen. 139 (1996) 43-49.

[3] M.H.W. Sonnemans, Appl. Catal. A: Gen. 94 (1993) 215-229.

[4] (a) J.E. Rekoske, M.A. Barteau, J. Catal. 165 (1997) 57-72;

(b) M. Ponzi, C. Duschatzly, A. Carrascull, E. Ponzi, Appl. Catal., A 169 (1998) 373-379;

(c) D. Haffad, A. Chambellan, J.C. Lavalley, J. Mol. Catal. A 168 (2001) 153-164.

[5] N. Mizuno, M. Misono, Chem. Rev. 98 (1998) 171-217.

[6] M.P. Atkins, US Patent 5,616,815 (1997).

[7] G.J. Haining, US Patent 5,714,429 (1998).

[8] A.V. Ivanov, E. Zausa, Y. Ben Taarit, N. Essayem, Appl. Catal., A 256 (2003) $225-242$.
[9] L.R. Pizzio, C.V. Cáceres, M.N. Blanco, Appl. Catal. A: Gen. 167 (1998) 283-294

[10] A. Fujishima, T.N. Rao, D.A. Tryk, J. Photochem. Photobiol. C: Photochem. Rev. 1 (2000) 1-21.

[11] J.-M. Herrmann, Catal. Today 53 (1999) 115-129.

[12] H. Park, W. Choi, J. Phys. Chem. B 107 (2003) 3885-3890.

[13] A. Hiskia, A. Mylonas, E. Papaconstantinou, Chem. Soc. Rev. 30 (2001) 62-69.

[14] R.C. Chambers, C.L. Hill, Inorg. Chem. 30 (1991) 2776-2781.

[15] V. Balzani, F. Bolleta, M.T. Gandolfi, M. Maestri, Top. Curr. Chem. 75(1978) 1-64.

[16] E. Papacostantinou, Chem. Soc. Rev. 18 (1989) 1-31.

[17] Y. Guo, C. Hu, J. Mol. Catal. A 262 (2007) 136-148.

[18] I.A. Weinstock, Chem. Rev. 98 (1998) 113-170.

[19] J. Kiwi, M. Grätzel, J. Phys. Chem. 91 (1987) 6673-6677.

[20] M. Yoon, J.A. Chang, Y. Kim, J.R. Choi, K. Kim, S.J. Lee, J. Phys. Chem. B 105 (2001) 2539-2545.

[21] R. Ozer, J.L. Ferry, Environ. Sci. Technol. 35 (2001) 3242-3246.

[22] R. Ozer, J.L. Ferry, J. Phys. Chem. B 106 (2002) 4336-4342.

[23] C. Chen, P. Lei, H. Ji, W. Ma, J. Zhao, H. Hidaka, N. Serpone, Environ. Sci. Technol. 38 (2004) 329-337.

[24] Y. Yang, Y. Guo, C. Hu, Y. Wang, E. Wang, Appl. Catal., A 273 (2004) 201-210.

[25] G. Marcì, E. Garcia-Lopez, L. Palmisano, D. Carriazo, C. Martin, V. Rives, Appl. Catal. B 90 (2009) 497-506, and references therein.

[26] A. Micek-Ilnicka, J. Mol. Catal. A 308 (2009) 1-14.

[27] Y. Yang, Q. Wu, Y. Guo, C. Hu, E. Wang, J. Mol. Catal. A 225 (2005) 203-212.

[28] M.T. Pope, Heteropoly and isopolyoxometalates, Springer-Verlag, New York, 1983.

[29] C. Rocchiccioli-Deltcheff, M. Fournier, R. Franck, R. Thouvenot, Inorg. Chem. 22 (1983) 207-216.

[30] J. Navarrete, T. López, R. Gómez, F. Figueras, Langmuir 12 (1996) 4385-4390.

[31] E. Fontananova, L. Donato, E. Drioli, L.C. López, P. Favia, R. D’Agostino, Chem. Mater. 18 (2006) 1561-1568.

[32] M.T. Pope, G.M. Varga Jr., Inorg. Chem. 5 (1966) 1249-1254 